\title{
QUALITY OF CARE AND CONTRACEPTIVE PILL DISCONTINUATION IN RURALEGYPT
}

\author{
MOHAMED M. ALI \\ Centre for Population Studies, L ondon School of Hygiene \& Tropical M edicine, \\ 49-51 Bedford Square, L ondon W C 1B 3DP
}

\begin{abstract}
Summary. Indicators of family planning service access and quality were generated using the Egypt DHS-I (1988) and the Egypt Service A vailability Survey (1989), and linked to episodes of contraceptive pill use. M ultilevel analysis was used to ascertain whether or not these access and quality indicators influence the continuation of pill use, net of women's socioeconomic, demographic and motivational characteristics. A model with random components at the cluster and women levels was fitted for all reasons of discontinuation, except desire for pregnancy, at 24 months of use. $N$ et of women's background characteristics, the results show that facilities with smaller numbers of health personnel trained in family planning, a lack of access to facilities with female doctors and a lack of range of available methods are associated with a high risk of discontinuation of pill use for all reasons except desire for pregnancy.
\end{abstract}

\section{Introduction}

The quality of family planning services received huge attention in the 5 years following publication of J udith Bruce's 'quality of care' framework (Bruce, 1990). A renewed determination to improve family planning provision is, of course, extremely welcome, but in view of resource constraints, a sharper focus and a clearer sense of priorities is urgently needed. Some dimensions of quality are desirable, or even essential, in any circumstances. Included under this heading are the technical competence of staff, the observance of standards of hygiene and the treatment of clients with dignity and respect. No research is needed to support these objectives, though monitoring of standards is important.

However, other dimensions of quality are not absolute prerequisites in the same sense. It is not immediately obvious, for instance, which types of counselling, or how much or when, should be provided to clients, or which procedures should be advocated for follow-up. Similarly, the degree of privacy offered, the amount of medical screening that takes place, waiting time at clinics and geographical density of services are not readily amenable to simple universal recommendations. Practical 
guidelines on these and many other aspects of service provision should be based, not on assertion, but on empirical evidence. This evidence can be grouped into three main types: direct investigation of the priorities of clients and potential clients; experiments to assess the impact of specific improvements in service provision; and nonexperimental analyses that seek to link community-level data on service characteristics to individual-level data on acceptability or satisfaction.

The first type of evidence is relatively simple to obtain by largely qualitative research on the views and preferences of clients and potential clients. Providers need to know which characteristics of services matter most to individuals. However, despite the current emphasis on the user's perspective, it is disappointing how little research has been devoted to this topic, although a useful start has been made (R eproductive $\mathrm{H}$ ealth M atters for WHO, 1999).

The second type of evidence seeks to establish priorities for improvement of services, not by direct questioning of clients, but indirectly in an experimental or quasi-experimental manner. I deally, some improvement of service provision - perhaps a change in the counselling or follow-up procedures - should be introduced in an experimental way and its effect on client satisfaction assessed. Only those innovations or improvements that pass a simple cost-effectiveness criterion should be considered for widespread application. Though some interesting experiments were conducted in the early 1970s (e.g. Bang, 1971; Chan, 1971), there appears to have been very little recent research of this type. One of several possible reasons for this is the difficulty of selecting suitable outcome measures. Direct measures of client satisfaction have not proved useful. In the early 1980s, many contraceptive prevalence surveys included simple questions on satisfaction with services. Typically $90 \%$ or more of current or past clients expressed satisfaction. This result merely implies that the majority of women are reluctant to express open criticism of government services. An alternative measure of satisfaction - albeit a less direct one - is the willingness of clients to persist in the use of chosen contraceptive methods and willingness to continue to use the same service or family planning outlet. This measure is based on the assumption that women who are satisfied with a service will be more likely to continue use of methods and services than women who are dissatisfied.

The third type of evidence links individual-level data on acceptability or satisfaction with cluster- or community-level data on quality of services. This paper presents evidence of this third type. The research is built on two earlier studies that used life table analysis to compare methods and cause-specific continuation rates, and a multivariate analysis to determine the factors influencing discontinuation (Ali \& Cleland, 1995, 1999). The focus here is on factors influencing continuation of pill use in rural Egypt, as this is the most commonly used contraceptive method in rural Egypt. The analysis highlights the effect on pill continuation of various indicators of service access and quality, net of women's socioeconomic, demographic and motivational characteristics, and prior experience of the method. It is believed that this is one of the very few studies that has attempted to use DHS service availability data to examine contraceptive continuation rates. Though the results cannot be as convincing as those from an experimental study, they may nevertheless reveal whether the willingness and ability of women to persist with use of oral contraceptives is conditioned by the service environment. 
There are at least two objections to the use of method-continuation rates as an indirect indicator of client satisfaction. First, one common reason for discontinuation is the desire for another pregnancy. This motive for stopping implies no dissatisfaction with the service or method. This objection can be overcome easily by censoring episodes that end for this reason. The second objection concerns termination of use of one method in order to switch to another. Such method switching may be an indication of access to a wide range of methods and thus a reflection of high quality services rather than ones of poor quality. This objection, in principle, introduces bias, but it is of little practical significance in this study as of all use-episodes studied, only $7 \%$ involved switching to another method within 3 months of stopping.

\section{Data}

The data for this analysis were drawn from the Egypt $1988 \mathrm{D}$ emographic and $\mathrm{H}$ ealth Survey (EDHS-I), and the Egypt 1989 Service Availability Survey (ESAS), linked together by cluster number. The EDHS-I provided information on episodes of contraceptive use within the previous 5 years (approximate time of start, duration of use and reason for stopping, where appropriate). The individual record data manipulation and the limitation of the data have been explained elsewhere (Ali \& Cleland, 1995, 1999). The data manipulation for the service availability survey described here is explained below.

The ESAS questionnaire was designed to collect detailed information about the access to services and their quality in each of the 120 rural villages selected in the EDHS-I. To achieve this, information was gathered at the village level about five types of service facilities: the number of facilities in the community, and the distance/travel time (measured in kilometres/minutes) to the nearest facility of each type. In order to obtain information about the quality of services, all facilities located in the village, or the nearest facility of each type, were visited.

The first section of the questionnaire collected information about geographical characteristics and general information about the facilities and services available in the village or within $30 \mathrm{~km}$ of it. This included: type of public transportation; presence of schools, telephone and post office and similar services in the village, or distance to them; whether the village was covered by a traditional birth attendant (daya), a trained nurse-midwife, community-based family planning (CBFP) workers or a family planning nurse. The second section of the questionnaire collected detailed information about five types of service facilities, if available in the village or within $30 \mathrm{~km}$. These facilities were: (1) government hospitals, (2) government M CH centres, (3) government family planning clinics, (4) private voluntary family planning clinics, and (5) pharmacies. F rom each surveyed facility, detailed information was collected about the distance to the facility from the village centre and the approximate time required to reach the facility, type of services offered, and number of staff personnel with particular skills. For more information on these surveys see Sayed et al. (1989) and Sayed (1991).

Informants for the survey varied depending on which section of the questionnaire was being addressed. Information on general and geographical characteristics was 
obtained from the village headman or an official working in the village. Information on facilities was gathered from relevant staff at each facility being surveyed.

From the many village and facility characteristics that were investigated in the ESAS, the following three main categories of characteristics were selected, either from the original data file or derived from several other variables. F actor analysis was used to provide a summary score for different dimensions of access and quality of services.

(a) Village characteristics were represented by two variables:

1. Type of main access road into village in which cluster was located, classified as paved road or other (which included unpaved or no road).

2. Distance (in $\mathrm{km}$ ) to the nearest town grouped into: $1-5,6-10$ and $11+\mathrm{km}$.

(b) A ccess to services was represented by the following three variables:

1. Standardized score for the total number of trained health personnel who provided family planning information or services. These included trained nurses/ midwives, trained dayas, CBFP workers and FP nurses in the village, grouped into: low, moderate and high.

2. Number of facilities that provide family planning and $\mathrm{MCH}$ services in the village or within $30 \mathrm{~km}$ of the village, grouped into: $<5$ and $5+$.

3. A proximity standardized score that represented the mean distance/travelling time from the centre of the village to family planning facilities, grouped into: below average and average or above.

(c) The quality of services available to each village was represented by three variables:

1. The percentage of family planning doctors who were female: this measure was computed from data on the total number of male and female doctors who provided family planning services in all facilities that were in the village or within $30 \mathrm{~km}$ grouped into: none, up to $25 \%$ and $26 \%+$.

2. A summary of the scores of staff competence and training; this was derived from data on numbers of staff with family planning training, numbers trained in IU D insertion and numbers of medical doctors who insert IUDs on a regular basis. A standardized score was computed for each facility, then summarized and grouped into: low, moderate and high.

3. A score that summarizes the range of family planning methods available in facilities, grouped into: below average and average or above.

It cannot be claimed that these measures of access and quality are ideal or comprehensive. For instance, no data were available on the nature of provider-client interactions, which is thought by many to be a crucial dimension of quality (Bruce, 1990). M oreover it was not possible to match individual users to specific facilities. $\mathrm{N}$ evertheless, the information collected in the ESAS is exceptionally detailed and is certainly sufficient to establish whether or not certain aggregate components of access and quality exert an influence on oral contraceptive use-continuation. 
Table 1. A vailability of health and family planning services or family planning personnel

\begin{tabular}{|c|c|c|c|}
\hline & \multicolumn{3}{|c|}{ Villages with: } \\
\hline & None & 1 & $2+$ \\
\hline \multicolumn{4}{|l|}{ Type of facility } \\
\hline G overnment hospital & 0.8 & $98 \cdot 3$ & 0.8 \\
\hline Government $\mathrm{M} \mathrm{CH}$ & $4 \cdot 2$ & $95 \cdot 0$ & 0.8 \\
\hline Government F P clinic & $8 \cdot 3$ & $89 \cdot 2$ & $2 \cdot 5$ \\
\hline Private F P clinic & $50 \cdot 8$ & $49 \cdot 2$ & 0.0 \\
\hline Pharmacy & 0.0 & $75 \cdot 8$ & $24 \cdot 2$ \\
\hline \multicolumn{4}{|l|}{ H ealth \& FP personnel } \\
\hline Daya trained in $\mathrm{FP}$ & $70 \cdot 8$ & $12 \cdot 5$ & $16 \cdot 7$ \\
\hline Trained nurse/midwife & $30 \cdot 0$ & $15 \cdot 8$ & $54 \cdot 2$ \\
\hline CBFP worker & $53 \cdot 3$ & $32 \cdot 5$ & $14 \cdot 2$ \\
\hline FP nurse & $31 \cdot 7$ & $38 \cdot 3$ & $30 \cdot 0$ \\
\hline
\end{tabular}

\section{M ethods}

The resulting file had a three-level hierarchical structure. Times of 3-month interval (level 1) were nested within-woman (level 2) and women were nested within-village (level 3). (Since fewer than $16 \%$ of respondents reported more than one episode of pill use, the episode level was ignored.)

The hypothesis used was that respondent and service characteristics jointly influence method-continuation, and that the outcome of interest is a binary response (Ali \& Cleland, 1999). A multilevel complementary log-log (CLL) regression model was to used to estimate, simultaneously, the effect of women's characteristics and access and quality of care indicators at the village level on pill discontinuation for all reasons, except desire for pregnancy, in rural Egypt.

A simple multilevel extension of the standard complementary log-log ( $C L L$ ) model was used. L et $\pi_{i j k}$ denote the probability of discontinuation at the $k^{\text {th }}$ time interval for the $\mathrm{j}^{\text {th }}$ woman at the $\mathrm{i}^{\text {th }}$ village. Conditional on random effects $z_{i j}$ and $z_{i}$ representing unobserved characteristics of the women and the villages respectively, the CLL of the probability of $\pi_{\mathrm{ijk}}$ is given by the following equation:

$$
\log \left\{-\log \left(1-\pi_{\mathrm{ijk}}\right)\right\}=\mathrm{x}_{\mathrm{ijk}} \beta+\mathrm{w}_{\mathrm{ij}} \gamma+\mathrm{y}_{\mathrm{i}} \eta+\mathrm{z}_{\mathrm{ij}} \mathrm{u}_{\mathrm{ij}}+\mathrm{z}_{\mathrm{i}} \mathrm{v}_{\mathrm{i}}
$$

where $x_{i j k}, w_{i j}$ and $y_{i}$ are vectors of time interval, woman characteristics and village characteristics respectively, and $\beta, \gamma$ and $\eta$ are vectors of estimated parameter coefficients (the fixed part of the model). The terms $\mathrm{u}_{\mathrm{ij}}\left(\sim \mathrm{N}\left(0, \sigma_{\mathrm{u}}\right)\right)$ and $\mathrm{v}_{\mathrm{i}}(\sim \mathrm{N}(0$, $\left.\sigma_{v}\right)$ ) are error terms at the woman and village level respectively (the random part) and are assumed to be uncorrelated with the observed covariates. The above model is known as a random intercepts- or variance-component model (Longford, 1993). 
Table 2. Cumulative life table probabilities of discontinuation for all reasons except desire for pregnancy at 12 and 24 months per 100 episodes of pill use, by women's characteristics

\begin{tabular}{|c|c|c|c|}
\hline & \multirow{2}{*}{$\begin{array}{l}\text { No. of } \\
\text { episodes }\end{array}$} & \multicolumn{2}{|c|}{$\begin{array}{l}\text { Probability of } \\
\text { discontinuation }\end{array}$} \\
\hline & & 12 months & 24 months \\
\hline \multicolumn{4}{|l|}{ Socioeconomic } \\
\hline \multicolumn{4}{|l|}{ R egion of residence } \\
\hline Lower Egypt & 766 & $30 \cdot 2$ & $50 \cdot 6$ \\
\hline Upper Egypt & 285 & 39.6 & $54 \cdot 2$ \\
\hline \multicolumn{4}{|l|}{ Women's education } \\
\hline No education & 578 & $34 \cdot 3$ & $51 \cdot 3$ \\
\hline Primary & 375 & $31 \cdot 0$ & $51 \cdot 6$ \\
\hline Secondary + & 98 & $24 \cdot 6$ & $54 \cdot 4$ \\
\hline \multicolumn{4}{|l|}{ H usband's education } \\
\hline No education & 374 & $33 \cdot 8$ & $51 \cdot 4$ \\
\hline Primary & 471 & $32 \cdot 4$ & $51 \cdot 6$ \\
\hline Secondary+ & 206 & $29 \cdot 5$ & $51 \cdot 5$ \\
\hline \multicolumn{4}{|c|}{ Demographic and motivational } \\
\hline \multicolumn{4}{|c|}{ A ge group (years) } \\
\hline$<25$ & 363 & $39 \cdot 6$ & $64 \cdot 1$ \\
\hline $25-35$ & 492 & $29 \cdot 0$ & $46 \cdot 9$ \\
\hline $35+$ & 195 & $27 \cdot 8$ & $41 \cdot 7$ \\
\hline \multicolumn{4}{|c|}{ N umber of living children } \\
\hline $0-1$ & 149 & $46 \cdot 4$ & $64 \cdot 6$ \\
\hline $2-3$ & 380 & $35 \cdot 4$ & $57 \cdot 4$ \\
\hline $4+$ & 521 & $26 \cdot 6$ & $44 \cdot 0$ \\
\hline \multicolumn{4}{|c|}{ Desire for another child } \\
\hline A ctual $=$ desire & 189 & $30 \cdot 1$ & $49 \cdot 1$ \\
\hline A ctual $<$ desire & 272 & $44 \cdot 5$ & $69 \cdot 6$ \\
\hline A ctual>desire & 424 & $26 \cdot 7$ & $43 \cdot 4$ \\
\hline Not stated & 166 & $31 \cdot 4$ & $51 \cdot 3$ \\
\hline \multicolumn{4}{|l|}{ Prior use of pill } \\
\hline Didn't use & 721 & $38 \cdot 3$ & $57 \cdot 3$ \\
\hline Used before & 300 & $19 \cdot 6$ & $39 \cdot 3$ \\
\hline \multicolumn{4}{|l|}{ V illage characteristics } \\
\hline \multicolumn{4}{|c|}{$M$ ain access road into village } \\
\hline A sphalt or cement & 850 & $31 \cdot 2$ & $52 \cdot 2$ \\
\hline Other & 201 & $36 \cdot 7$ & $49 \cdot 2$ \\
\hline \multicolumn{4}{|c|}{ Distance to nearest town $(\mathrm{km})$} \\
\hline $1-5$ & 338 & $29 \cdot 1$ & $50 \cdot 2$ \\
\hline $6-10$ & 404 & 28.9 & $48 \cdot 3$ \\
\hline $11+$ & 309 & $41 \cdot 4$ & $57 \cdot 6$ \\
\hline
\end{tabular}


Table 2. Continued

\begin{tabular}{|c|c|c|c|}
\hline & \multirow{2}{*}{$\begin{array}{l}\text { No. of } \\
\text { episodes }\end{array}$} & \multicolumn{2}{|c|}{$\begin{array}{l}\text { Probability of } \\
\text { discontinuation }\end{array}$} \\
\hline & & 12 months & 24 months \\
\hline \multicolumn{4}{|c|}{ Access to services } \\
\hline \multicolumn{4}{|c|}{ Trained health personnel who provide F P score } \\
\hline Low & 249 & $38 \cdot 0$ & $54 \cdot 5$ \\
\hline M oderate & 377 & $35 \cdot 7$ & $56 \cdot 9$ \\
\hline $\mathrm{H}$ igh & 424 & $26 \cdot 1$ & $45 \cdot 0$ \\
\hline \multicolumn{4}{|c|}{ N umber of facilities providing FP } \\
\hline$\leq 4$ & 494 & $35 \cdot 1$ & $56 \cdot 1$ \\
\hline $5+$ & 557 & $29 \cdot 7$ & $46 \cdot 8$ \\
\hline \multicolumn{4}{|c|}{ Proximity score } \\
\hline$<$ A verage & 664 & $29 \cdot 8$ & $50 \cdot 8$ \\
\hline A verage+ & 387 & $37 \cdot 0$ & $52 \cdot 9$ \\
\hline \multicolumn{4}{|l|}{ Q uality of care } \\
\hline \multicolumn{4}{|c|}{ Percentage female among M Ds who provide F P } \\
\hline None & 225 & $36 \cdot 7$ & $52 \cdot 8$ \\
\hline Up to $25 \%$ & 560 & $32 \cdot 8$ & $52 \cdot 9$ \\
\hline $26-75 \%$ & 265 & $27 \cdot 5$ & $47 \cdot 3$ \\
\hline \multicolumn{4}{|c|}{ Staff competence score } \\
\hline Low & 345 & $32 \cdot 4$ & $52 \cdot 3$ \\
\hline M oderate & 343 & $31 \cdot 6$ & $52 \cdot 4$ \\
\hline $\mathrm{H}$ igh & 362 & $32 \cdot 9$ & $49 \cdot 7$ \\
\hline \multicolumn{4}{|c|}{$\mathrm{R}$ ange of $\mathrm{FP}$ methods available score } \\
\hline$<$ A verage & 466 & $32 \cdot 1$ & $51 \cdot 1$ \\
\hline A verage+ & 584 & $32 \cdot 5$ & $51 \cdot 7$ \\
\hline
\end{tabular}

The parameters of the above model were estimated using the second-order Penalized Quasi-likelihood (PQL) approximation implemented in the Statistical Package M Ln (Goldstein, 1991, 1995; R asbash \& Woodhouse, 1995). Prior to the multivariate analysis, the single-decrement life table technique was used to calculate the crude cumulative probabilities of discontinuation of pill use at 12 and 24 months by women's and village characteristics.

\section{Results}

The selected villages share similar physical characteristics. Seventy-five per cent have a nuclear settlement pattern, $81 \%$ are located within $15 \mathrm{~km}$ of the nearest city or town, $77 \%$ are accessible by minibus or collective taxi and $87 \%$ have paved roads. With regard to health and family planning infrastructure, more than $90 \%$ of the villages are located within $30 \mathrm{~km}$ of the three types of government facilities. 
Pharmacies are accessible from all villages, while only half of the villages are located within $30 \mathrm{~km}$ of private family planning services (Table 1 ).

Rural women receive health and family planning services through a group of government and private sector facilities working at the village level. Table 1 shows the distribution of villages according to the number of health and family planning personnel. Only $29 \%$ of the sampled villages have at least one trained daya; $70 \%$ are covered by one or more trained nurse/midwife, almost half by CBFP workers and $60 \%$ by a family planning nurse.

Table 2 shows the cumulative life table probabilities of discontinuation at 12 and 24 months after initiation of use for all reasons except desire for pregnancy, by women's and village characteristics, and by indicators of service availability and quality. A s explained earlier, the reason for excluding discontinuation in order to have another child is that this motive for stopping is unlikely to reflect problems of access to, or quality of, services. Conversely, discontinuation for most other reasons may reflect inadequacies of services.

As expected, cumulative probabilities of discontinuation for the pill tend to be higher among respondents who live in settings with sparse or poor quality family planning services. Typically, women resident in villages with fewer health personnel trained in providing family planning information and methods, or who have access to fewer facilities that provide FP/M CH services, are more likely to cease use of the pill than respondents in better-served villages. Similarly, the percentage of female family planning doctors and the 'information provided to clients' score are related to contraceptive discontinuation in the anticipated direction. However, neither staff competence nor range of methods available appears to exert an influence on discontinuation.

$R$ andom effect discrete-time event hazard models were fitted up to 24 months. Table 3 shows the crude and adjusted relative risks ( $R$ ) of discontinuation relative to continued use of the method according to village and service availability and quality covariates. Significant effects $(p<0.05)$ are identified in bold typeface. R elative risks that are greater than 1.0 indicate a higher risk of discontinuation than the risk for the reference category of each covariate.

The effects of most of the covariates on continuation are in the expected directions with very few exceptions, such as the effect of distance to the nearest town and range of family planning methods available.

These initial results serve as a way of screening for the important predictors to be considered in reaching a final parsimonious model using forward and backward procedures. Table 4 presents the parameter estimates and standard errors with relative risks (RR) for the final selected random effect hazard model.

The results for discontinuation for all reasons except desire for pregnancy are summarized in Table 4. A low number of health personnel trained in family planning is associated with a high risk of discontinuation. Respondents living in villages with low numbers are $50 \%$ more likely to stop using the pill within 2 years of initiation than respondents living in villages with higher numbers. Women having no access to facilities with female family planning doctors are more likely to discontinue use of the pill $(R R=1 \cdot 54)$. A $n$ additional quality indicator enters the model with a borderline level of significance, i.e. range of available methods. Contrary to expectations, a narrower range of available methods is associated with lower rather than higher 
Table 3. Crude and adjusted relative risks (RRS) of discontinuation for all reasons except desire for pregnancy at 24 months of pill use, by village characteristics, access to services and quality of care indicators

RR $\quad 95 \% \mathrm{Cl}$

\section{Village characteristics}

$M$ ain access road into village

Distance to nearest town $(\mathrm{km})$

N umber of facilities providing F P

Proximity score

\section{Access to services}

Trained health personnel who provide F P score

Staff competence score

$R$ ange of $F P$ methods available score

\section{Q uality of care}

\begin{tabular}{|c|c|c|c|}
\hline \\
\hline \multicolumn{4}{|c|}{ Other Crude } \\
\hline$(1-5)$ & A djusted & 0.87 & $10 \cdot$ \\
\hline \multirow{2}{*}{$6-10$} & Crude & 0.94 & $(0.7$ \\
\hline & A djusted & 0.97 & $(0.73-1 \cdot 28)$ \\
\hline \multirow[t]{2}{*}{$11+$} & Crude & $1 \cdot 17$ & $(0.92-1.50)$ \\
\hline & A djusted & $1 \cdot 15$ & $(0.87-1.53)$ \\
\hline
\end{tabular}

(High) M oderate

Crude 1.32 (1.05-1.67)

A djusted $1.25 \quad(0.97-1.61)$

Low Crude 1.38 (1.06-1.80)

A djusted 1.34 (1.00-1.80)

$(4+)$

1-3 Crude $1.17 \quad(0.96-1.44)$

A djusted $0.97 \quad(0.76-1.25)$

(A verage+)

$<$ A verage Crude $1.18 \quad(0.96-1.49)$

A djusted $1.28 \quad(0.97-1.69)$

Percentage female among M D s who provide F P (26\%-75\%)

Up to $25 \%$ Crude $1.26 \quad(0.99-1.61)$

A djusted $1.12 \quad(0 \cdot 85-1 \cdot 48)$

None Crude $1.46 \quad(1.10-1.96)$

A djusted $1.29 \quad(0.91-1.83)$

(High)

Moderate Crude $1.01 \quad(0.80-1.29)$

A djusted $0.93 \quad(0.70-1.25)$

Low Crude $1.17 \quad(0.92-1.49)$

A djusted $1.00 \quad(0.72-1.37)$

(A verage+)

$<$ A verage Crude $0.87 \quad(0.71-1.06)$

A djusted $\quad 0.70 \quad(0.54-0.91)$

R eference categories are in parentheses.

discontinuation. One possible reason is that women who face a restricted choice of methods have less freedom to switch to another method and therefore persist (albeit reluctantly) with the initial method. Other significant predictors are: a small number 
Table 4. Parameter estimates, standard error and R R for random effect discrete-time model comparing all reasons of discontinuation of pill use (except desire for pregnancy) with still using at 24 months

\begin{tabular}{|c|c|c|c|}
\hline & Coeff. & (SE) & $\mathrm{RR}$ \\
\hline \multicolumn{4}{|l|}{ Fixed part } \\
\hline Constant & -3.41 & $(0.248)$ & \\
\hline \multicolumn{4}{|c|}{$\mathrm{N}$ umber of living children } \\
\hline $4+$ & 0.00 & & \\
\hline $2-3$ & 0.39 & $(0 \cdot 147)$ & $(1.48)$ \\
\hline $0-1$ & 0.36 & $(0.211)$ & $(1 \cdot 43)$ \\
\hline \multicolumn{4}{|c|}{ Desire for another child } \\
\hline A ctual = desire & 0.00 & & \\
\hline A ctual $<$ desire & 0.47 & $(0 \cdot 169)$ & $(1.60)$ \\
\hline A ctual >desire & 0.08 & $(0 \cdot 177)$ & $(1.08)$ \\
\hline $\mathrm{N}$ ot stated & 0.21 & $(0 \cdot 188)$ & $(1 \cdot 23)$ \\
\hline \multicolumn{4}{|l|}{ Prior use of pill } \\
\hline U sed before & 0.00 & & \\
\hline Didn't use before & 0.55 & $(0 \cdot 122)$ & $(1 \cdot 73)$ \\
\hline \multicolumn{4}{|c|}{ N umber of trained health personnel who provide FP score } \\
\hline High & 0.00 & & \\
\hline M oderate & 0.36 & $(0 \cdot 140)$ & $(1 \cdot 43)$ \\
\hline Low & 0.47 & $(0 \cdot 156)$ & $(1 \cdot 60)$ \\
\hline \multicolumn{4}{|c|}{ Percentage female among M Ds who provide FP } \\
\hline $26 \%-75 \%$ & 0.0 & & \\
\hline Up to $25 \%$ & 0.23 & $(0 \cdot 151)$ & $(1 \cdot 26)$ \\
\hline None & 0.43 & $(0.176)$ & $(1 \cdot 54)$ \\
\hline \multicolumn{4}{|c|}{ R ange of family planning methods available } \\
\hline A verage+ & 0.00 & & \\
\hline$<$ A verage & -0.24 & $(0 \cdot 121)$ & $(0.80)$ \\
\hline \multicolumn{4}{|l|}{$\mathrm{R}$ andom part } \\
\hline$\sigma_{u}^{2}$ (woman level) & $0 \cdot 112$ & $(0.098)$ & \\
\hline$\sigma_{v}^{2} \quad($ village level) & 0.085 & $(0.041)$ & \\
\hline
\end{tabular}

of living children, desire for more children and lack of prior experience with oral contraception.

The random part of the model measures the extent of the variability in discontinuation rates across women and villages that is not accounted for by the covariates measured at these levels. The result shows that there is an unexplained significant heterogeneity between villages that cannot be explained by the fixed part parameters.

\section{D iscussion}

At the start of this paper, it was asserted that the debate on the quality of family planning services needs to be sharpened. In view of resource constraints, priority 
should be given to improvements that will be most valued by clients and potential clients. To reach a decision, empirical evidence rather than rhetoric is required.

This paper represents an exploratory attempt to ascertain whether information from cross-sectional surveys, such as those conducted under the auspices of the DHS, can be useful in this regard. A large number of DHS enquiries have collected very detailed information on contraceptive continuation and on the number, nature and quality of family planning services near sampled clusters. By linking these two types of data, relationships between indicators of service access and quality and contraceptive continuation can be explored. Thus far, there is little evidence as to the effect of service quality on service use or service continuation, nor are the few available results consistent. A multi-site study revealed no effects of several quality indicators (Huezo et al., 1993). Conversely, a study in Bangladesh showed a large effect of quality of outreach services (Huezo et al., 1993; K oenig et al., 1997). Similarly an earlier study in M exico showed that the amount of information imparted to clients had a positive influence on continuation (K eller, 1973).

The length of an episode of contraceptive use is not an ideal measure, even after exclusion of episodes that are stopped because the couple wanted another child or because of switching to another method. Continued use of a facility or a service would have been more appropriate for an investigation of the effects of service quality on family planning behaviour. However, data on continuity of use of the service facilities were not collected in the DHS and therefore there was no alternative but to use discontinuation of a particular method as an indirect, surrogate measure of satisfaction with services.

In view of the crude nature of the outcome variable, it is surprising that positive effects of service access and quality on oral pill continuation were found. These results are even more surprising when it is taken into account that use-continuation could be related to the general service environment but not to the specific facilities used by individual women. $\mathrm{N}$ evertheless, it appears from the analysis that both the number of family planning facilities in the vicinity and access to female family planning doctors may influence the ability and willingness of couples to be prolonged and successful users of oral contraception. Other indicators of access and quality had no effect on use-continuation.

The more important of these positive findings relates to the presence of female family planning doctors. A pproximately $25 \%$ of pill users had no ready access to a female family planning doctor (i.e. no facility within $30 \mathrm{~km}$ of the village had such a staff member). Oral contraceptive users in these settings experienced 1.45 times the risk of stopping use of the pill within 24 months than women living in villages where more than one-quarter of family planning doctors were women. W hile this association falls short of proof that there is a direct causal link, it is highly suggestive and extremely plausible, and certainly warrants further investigation. The training and posting of more female doctors could represent an important step in improvement of service quality in rural Egypt.

\section{R eferences}

A li, M. \& C Cleland, J. (1995) Contraceptive discontinuation in six developing countries: a cause-specific analysis. Int. Fam. Plann. Perspect. 21, 92-97. 
A LI, M . \& C Leland, J . (1999) Determinants of contraceptive discontinuation in six developing countries. J. biosoc. Sci. 13, 343-360.

$B_{A N G}$ S. (1971) K orea: the relationship between IU D retention and check-up visits. Stud. Fam. Plann. 2(5), 110-112.

BRUCE, J. (1990) F undamental elements of the quality of care: a single framework. Stud. Fam. Plann. 21, 61-91.

Chan, K. C. (1971) Hong K ong: Report of the IU D reassurance project. Stud. Fam. Plann. 2(11), 225-233.

G oldsteIn, H . (1991) N onlinear multilevel models, with application to discrete response data. Biometrika 78(1), 45-51.

G oldstern, H. (1995) M ultilevel Statistical M odels (2 ${ }^{\text {nd }}$ edition). Edward A rnold, London.

Huezo, C. M., M alhotra, V., Sloggett A.\& Cleland J. (1993) A cceptability and continuation of use of contraceptive methods: a multicentre study. In: Proceedings of the XIIIth W orld Congress of Gynaecology and Obstetrics, Vol. 1, pp. 111-135. Edited by E. S. Teoh, S. S. R atnam \& Sir M. M acN aughton.

K eller, A. (1973) Patient attrition in five M exico City family planning clinics. In: Clinics, Contraception and Communication. Edited by J. M. Stycos. Des Moines, M eredith Corporation.

K oenig, M . A ., H ossain, M . B. \& Whittaker, M . (1997) The influence of quality of care upon contraceptive use in rural Bangladesh. Stud. Fam. Plann. 28(4), 278-289.

L ONGFord, N. T. (1993) Random Effects M odels. Clarendon Press, Oxford, UK.

Rasbash, J. \& W Oodhouse, G. (1995) M Ln Command Reference. London Institute of Education.

R eproductive Health M Atters For WHO (1999) Beyond A cceptability: U sers' Perspectives on Contraception. London.

R ODRIGUEZ, G . \& G OLDMAN, N. (1995) A n assessment of estimation procedures for multilevel models with binary responses. J RSS(A) 158(1), 73-89.

SAYED, H. A. (1991) Egypt Service Availability Survey. Cairo Demographic Centre, Cairo, Egypt and IRD/M acro International, Inc., Columbia, MD, USA.

Sayed, H. A., Osman, M. I., El-Zanaty, F.\& W Ay, A. A. (1989) Egypt Demographics and Health Survey 1988. Egypt National Population Council and Institute for Resource D evelopment/M acro Systems, Inc. 